\title{
ANALISIS POTENSI EKONOMI DI SEKTOR DAN SUBSEKTOR PERTANIAN, KEHUTANAN DAN PERIKANAN KABUPATEN JEMBER
}

\author{
Ahmad Rizani \\ Universitas Borneo Tarakan \\ ahmadrizani@yahoo.co.id
}

\begin{abstract}
This study aims to examine the economic potential in the sector and sub-sector of agriculture, forestry and fishery of Jember Regency. In addition, this study also identifies and determines the leading sectors and sub-sectors in Jember Regency to provide an overview of the leading economic activities that can be developed in increasing the economic potential in Jember District. Analyzer used in this research include analysis of Shift-Share, Location Quotient (LQ), and Growth Ratio Model (MRP). From the research result, it can be seen that: (1) shift-share analysis shows Jember Regency economy during 2010-2015 period increased by Rp2,412.3 billion. The improvement of economic performance in Jember Regency can be seen from positive sector of agriculture sector, forestry and fishery; (2) Based on the analysis of Location Quotient $(L Q)$ sector and the leading sub-sector in Jember Regency there is 1 sector and 1 sub-sector having average LQ> 1 or sector and subsector of the (potential) ie agriculture, farming, and plantation subsector; (3) Growth Ratio Model (MRP) analysis shows that the dominant sectors of growth and large contribution include estate crop sub-sector, agriculture and hunting services sub sector, forestry and logging sector, and fishery sector; (4) weighted results based on Shift-Share, Location Quotient (LQ) and Growth Ratio $(M R P)$ analysis were obtained by the highest ranking sub-category of the most potential weighted crops sub-sector.
\end{abstract}

Keywords: Economic Potential, Shift-Share, Quotient Location (LQ), Growth Ratio Model (MRP)

\section{Abstrak}

Penelitian ini bertujuan untuk mengkaji potensi ekonomi di sektor dan subsektor pertanian, kehutanan dan perikanan Kabupaten Jember. Di samping itu, penelitian ini juga mengidentifikasi dan menentukan sektor dan subsektor unggulan di Kabupaten Jember untuk memberikan gambaran kegiatan ekonomi unggulan yang dapat dikembangkan dalam meningkatkan potensi ekonomi di Kabupaten Jember. Alat analisis yang digunakan dalam penelitian ini meliputi analisis Shift-Share, Location Quotient (LQ), dan Model Rasio Pertumbuhan (MRP). Dari hasil penelitian diperoleh bahwa : (1) analisis shift-share menunjukkan perekonomian Kabupaten Jember selama periode 2010-2015 mengalami peningkatan sebesar Rp2.412,3 milyar. Peningkatan kinerja perekonomian di Kabupaten Jember tersebut dapat dilihat dari sektor dan subsektor pertanian, kehutanan dan perikanan yang bernilai positif; (2) berdasarkan analisis Location Quotient (LQ) sektor dan subsektor unggulan di Kabupaten Jember terdapat 1 sektor dan 1 subsektor yang mempunyai rata-rata LQ>1 atau sektor dan subsektor yang unggulan (potensial) yaitu sektor pertanian, peternakan, perburuan \& jasa pertanian dan subsektor tanaman perkebunan; (3) analisis Model Rasio 
Pertumbuhan (MRP) menunjukkan bahwa sektor yang dominan pertumbuhan dan kontribusi yang besar meliputi subsektor tanaman perkebunan, subsektor jasa pertanian dan perburuan, sektor kehutanan dan penebangan kayu, dan sektor perikanan; (4) hasil pembobotan berdasarkan analisis Shift-Share, Location Quotient (LQ), dan Model Rasio Pertumbuhan (MRP) diperoleh subsektor berdasarkan peringkat tertinggi hasil pembobotan yang paling potensial yaitu subsektor tanaman perkebunan.

Kata Kunci : Potensi Ekonomi, Shift-Share, Location Quotient (LQ), Model Rasio Pertumbuhan (MRP)

\section{PENDAHULUAN}

Istilah pembangunan dapat diartikan berbeda oleh masing-masing orang, daerah satu dengan lainnya maupun negara satu dengan negara lainnya. Dalam pelaksanaannya pembangunan disuatu daerah perlu memperhatikan permasalahan yang ada dan tantangan global yang akan dihadapi oleh daerah tersebut di masa depan dengan mengacu pada nilainilai luhur kepribadian bangsa untuk mewujudkan kehidupan masyarakat yang maju, mandiri, berkeadilan, sejahtera dan mempunyai moral dan etika yang mulia. Begitu juga dalam hal pembangunan ekonomi daerah yang merupakan serangkaian kegiatan yang dilaksanakan oleh pemerintah dan bersama-sama masyarakat dalam mengelola dan memanfaatkan sumber daya untuk meningkatkan taraf hidup masyarakat didaerah.

Secara

tradisional

pembangunan memiliki peningkatan yang terus menerus pada Gross Domestik Produk (GDP) atau Produk Domestik Bruto (PDB) suatu negara. Untuk daerah, makna pembangunan yang tradisional difokuskan pada PDRB suatu provinsi, kabupaten dan kota. Pembangunan ekonomi daerah adalah suatu proses dimana pemerintah daerah dan seluruh komponen masyarakat mengelola berbagai sumber daya yang ada dan membentuk suatu pola kemitraan untuk menciptakan suatu lapangan pekerjaan baru dan merangsang perkembangan kegiatan ekonomi dalam daerah tersebut. Tolok ukur keberhasilan pembangunan dapat dilihat dari pertumbuhan ekonomi, struktur ekonomi dan semakin kecilnya ketimpangan pendapatan antar penduduk, antar daerah dan antar sektor (Arsyad, 2004: 7).

Todaro (2000: 22) mengatakan bahwa pembangunan merupakan 
multidimensi dari suatu masyarakat untuk mencapai kehidupan yang lebih baik. Pembangunan ekonomi pada hakikatnya mengoptimalkan bagaimana peranan sumber daya dalam menciptakan kenaikan pendapatan yang terakumulasi pada sektor-sektor ekonomi yang tercermin pada besarnya tingkat pertumbuhan ekonomi rata-rata per tahun. Tujuan utama dari pembangunan ekonomi daerah tersebut adalah untuk menciptakan kesejahteraan bagi seluruh masyarakat yang ada di daerah itu. Di karenakan pembangunan ekonomi daerah melibatkan multisektor dan pelaku pembangunan maka dalam upaya mencapai tujuan tersebut, pemerintah daerah dan masyarakat setempat harus bersama-sama mengambil inisiatif dalam proses pembangunan daerah. Oleh sebab itu, pemerintah daerah beserta partisipasi masyarakat juga menggunakan sumber daya yang ada harus mampu menaksir potensi ekonomi sumber daya yang diperlukan untuk merencanakan dan membangun perekonomian daerah.

Dengan adanya otonomi daerah, maka terbuka peluang bagi pemerintah daerah untuk melakukan verifikasi dalam pembangunan sehingga mendorong pembangunan semakin maju. Dengan semakin luas wewenang pada pemerintah daerah dan juga tuntutan dalam perkembangan perekonomian, maka pemerintah daerah dituntut untuk berperan aktif dalam membuat terobosan yang mampu meningkatkan pendapatan, produksi, dan perekonomian dengan melakukan kegiatan ekonomi potensial dan unggulan dalam memenuhi kebutuhan daerah atau lokal dan juga meningkatkan kemampuan dalam pemenuhan permintaan pasar.

Faktor penting yang menentukan keberhasilan suatu pembangunan daerah adalah proses perencanaan, karena pembangunan ekonomi tidak bisa hanya diserahkan kepada mekanisme pasar. Perencanaan dapat didefinisikan sebagai suatu proses berkesinambungan yang mencakup keputusan atas pilihan-pilihan berbagai alternatif penggunaan sumber daya untuk mencapai tujuan tertentu pada masa yang akan datang (Arsyad, 2004: 19).

$$
\text { Widodo (2006: }
$$
mengatakan kegiatan perencanaan 
pembangunan untuk mengembangkan sektor ekonomi dimulai dengan melakukan identifikasi sektor unggulan atau potensial ekonomi daerah. Perencanaan pembangunan ekonomi memerlukan bermacam data statistik sebagai dasar berpijak dalam menentukan strategi kebijakan, agar sasaran pembangunan dapat dicapai dengan tepat. Ada dua faktor utama yang perlu diperhatikan dalam mengidentifikasikan potensi kegiatan ekonomi daerah. Pertama, sektor ekonomi yang unggul atau yang mempunyai daya saing dalam beberapa periode tahun terakhir dan kemungkinan prospek sektor ekonomi dimasa mendatang. Kedua, sektor ekonomi yang potensial untuk dikembangkan dimasa mendatang walaupun pada saat ini belum mempunyai tingkat daya saing yang baik. Dengan teridentifikasikannya potensi kegiatan ekonomi daerah maka dapat disusun kebijakan pembangunan yang berlandaskan pada upaya meningkatkan pertumbuhan ekonomi.

Beberapa uraian tersebut di atas menunjukkan bahwa penelitian tentang potensi ekonomi di sektor pertanian, kehutanan dan perikanan serta peranan subsektor perkebunan dalam pembangunan perekonomian Kabupaten Jember sangat penting untuk dikaji secara lebih terperinci.

Dengan mengetahui potensi ekonomi yang ada di Kabupaten Jember, maka perencanaan pembangunan daerah dalam menghadapi masa yang akan datang dapat lebih terarah serta dapat dijadikan dasar dalam penerapan kebijakan skala prioritas untuk mengoptimalkan pendayagunaan potensi ekonomi daerah guna mempercepat pertumbuhan ekonomi.

\section{METODE PENELITIAN}

\section{Analisis Shift-Share}

Dalam menentukan sektor-sektor yang berkembang disuatu daerah dengan melakukan perbandingan perkembangan ekonomi daerah lainnya digunakan Shift Share. Menurut Widodo (2006: 112-113) analisis Shift-Share adalah salah satu teknik kuantitatif yang biasa digunakan untuk menganalisis perubahan struktur ekonomi daerah relatif terhadap struktur wilayah administratif. Pengaruh pertumbuhan provinsi disebut pengaruh pangsa (Share), pengaruh bauran industri disebut proporsional shift atau 
mengukur perubahan relatif, dan pengaruh keunggulan kompetitif disebut differential shift dalam menentukan seberapa jauh daya saing industri lokal dengan perekonomian yang dijadikan acuan. Itulah sebabnya disebut teknik Shift Share.

Menurut Creamer (1943) teknik analisis Shift Share ini membagi pertumbuhan sebagai perubahan (D) suatu variabel wilayah seperti, pendapatan atau output selama kurun waktu tertentu menjadi pengaruh pertumbuhan provinsi $(\mathrm{N})$, industri mix (bauran industri) $M$, dan keunggulan kompetitif (C). Untuk menganalisis sektor $\mathrm{i}$ diwilayah $\mathrm{j}$ dirumuskan secara matematis sebagai berikut (lihat Soepono, 1993: 44):

$$
D_{i j}=N_{i j}+M_{i j}+C_{i j}
$$

Dimana :

$\mathrm{D}_{\mathrm{ij}} \quad=$ perubahan variabel PDRB wilayah referensi sektor dan sub sektor i diwilayah studi $\mathrm{j}$

$\mathrm{N}_{\mathrm{ij}} \quad=\mathrm{E}_{\mathrm{ij}} \cdot \mathrm{r}_{\mathrm{n}}$ (pertumbuhan wilayah referensi sektor dan sub sektor $\mathrm{i}$ diwilayah studi $\mathrm{j}$ )

$M_{i j}=E_{i j} \cdot\left(r_{i n}-r_{n}\right)$ (bauran industri wilayah referensi sektor dan sub sektor i diwilayah studi j)

$$
\begin{aligned}
\mathrm{C}_{\mathrm{ij}}= & \mathrm{E}_{\mathrm{ij} \cdot\left(\mathrm{r}_{\mathrm{ij}}-\mathrm{r}_{\mathrm{in}}\right) \quad \text { (keunggulan }} \\
& \text { kompetitif wilayah referensi } \\
& \text { sektor dan sub sektor } \mathrm{i} \\
& \text { diwilayah studi } \mathrm{j})
\end{aligned}
$$

Persamaan rij mewakili laju pertumbuhan pada sektor sektor dan sub sektor i diwilayah studi, rin mewakili laju pertumbuhan pada sektor sektor dan sub sektor i diwilayah referensi, rn adalah pertumubuhan ekonomi wilayah referensi, yang kemudian dapat dikemukakan sebagai berikut:

$\mathrm{rij}=\left(\mathrm{E}^{*_{\mathrm{ij}}}-\mathrm{E}_{\mathrm{ij}}\right) / \mathrm{E}_{\mathrm{ij}}$

$r_{\text {in }}=\left(E^{*}\right.$ in $\left.-E_{\text {in }}\right) / E_{\text {in }}$

$r_{n}=\left(E^{*}{ }_{n}-E_{n}\right) / E_{n}$

Dimana :

Eij = nilai tambah sektor dan sub sektor i diwilayah studi $\mathrm{j}$

Ein = nilai tambah sektor sektor dan sub sektor i di wilayah referensi

En $=$ pertumbuhan ekonomi wilayah referensi

Seluruh variabel diukur pada suatu tahun dasar dan tanda superscript $\quad(*)$ menunjukkan pertumbuhan ekonomi pada tahun akhir yang dianalisis. Untuk suatu wilayah, pertumbuhan nasional atau provinsi, bauran industri dan keunggulan kompetitif dapat 
ditentukan bagi suatu sektor atau dijumlah untuk semua sektor sebagai keseluruhan wilayah. Persamaan Shift Share untuk sektor tertentu (sektor dan sub sektor i) diwilayah tertentu (wilayah j) adalah:

$D_{i j}=E_{i j}\left(r_{n}\right)+E_{i j}\left(r_{i n}-r_{n}\right)+E_{i j}\left(r_{i j}-\right.$ rin)

\section{Analisis Location Quotient (LQ)}

Menurut Arsyad (2004: 315317) analisis Location Quotient (LQ) merupakan teknik yang digunakan untuk memperluas analisis Shift Share. Teknik ini membantu untuk menentukan kapasitas ekspor perekonomian suatu daerah dan derajat self-suffiency suatu sektor dimana Location Quotient (LQ) dipakai untuk mengukur konsentrasi dari suatu kegiatan (industri) dalam suatu daerah, yaitu dengan cara membandingkan peranannya dalam perekonomian daerah itu dengan peranan atau kegiatan industri sejenis dalam perekenomian regional ataupun nasional.

Menurut Tarigan (2007: 82) analisis Location Quotient (LQ) adalah salah satu indikator sederhana yang menunjukkan "kekuatan" akan besar dan kecilnya sektor pada suatu daerah dibandingkan sektor yang sama pada daerah yang lebih luas wilayahnya. Semakin tinggi nilai LQ suatu sektor berarti semakin tinggi pula competitive advantage daerah yang bersangkutan dalam mengembangkan sektor tersebut.

Dalam analisis Location Quotient (LQ) biasanya digunakan untuk mengidentifikasi Produk Domestik Regional Bruto suatu daerah dalam menentukan sektor unggulan (basis) dan bukan sektor unggulan (non basis). Bila sektor unggulan tersebut dikembangkan dengan baik dan benar, maka akan mempengaruhi pertumbuhan ekonomi daerah yang akan dapat meningkatkan pendapatan daerah secara optimal.

Perhitungan LQ bertujuan agar menggambarkan keunggulan komparatif suatu daerah dengan wilayah lainnya. Rumus yang digunakan dalam menentukan sektor basis atau sektor unggulan adalah:

$$
\mathbf{L Q}=\frac{E_{i j} / E_{j}}{E_{i n} / E_{n}}
$$

Keterangan :

LQ = Location Quotient sektor dan subsektor pertanian, kehutanan dan perikanan Kabupaten Jember 
$E_{i j}=$ PDRB sektor dan subsektor pertanian, kehutanan dan perikanan Kabupaten Jember

$E_{j}=$ Total PDRB sektor dan subsektor pertanian, kehutanan dan perikanan Kabupaten Jember Kabupaten Jember

$E_{\text {in }}=$ PDRB sektor dan subsektor pertanian, kehutanan dan perikanan Provinsi Jawa Timur

$E_{n}=$ Total PDRB sektor dan subsektor pertanian, kehutanan dan perikanan Provinsi Jawa Timur

Lebih jauh Bendavid-Val (1991) dalam Kuncoro (2004: 183) memberikan pengukuran terhadap derajat spesialisasi dengan kriteria sebagai berikut:

1) LQ > 1, berarti tingkat spesialisasi sektor tertentu pada tingkat daerah lebih besar dari sektor yang sama pada tingkat pusat (negara).

2) $\mathrm{LQ}=1$, berarti tingkat spesialisasi sektor tertentu pada tingkat daerah sama dengan sektor yang sama pada tingkat pusat (negara).

3) LQ > 1, berarti tingkat spesialisasi sektor tertentu pada tingkat daerah lebih kecil dari sektor yang sama pada ada tingkat pusat (negara).

\section{Model Rasio Pertumbuhan}

Menurut Yusuf (1999: 220-223) Model Rasio Pertumbuhan (MRP) digunakan untuk menganalisis sektor ekonomi potensial. Model ini merupakan modifikasi lebih lanjut dari analisis Shift-Share. Untuk merumuskan cara menganalisis Model Rasio Pertumbuhan adalah sebagai berikut:

1) Rasio pertumbuhan wilayah referensi adalah perbandingan antara laju pertumbuhan sektor $\mathrm{i}$ dengan laju pertumbuhan total kegiatan (PDB) diwilayah referensi, dengan rumusnya adalah:

$$
\operatorname{RPr}=\frac{\Delta \mathbf{E}_{\mathrm{ir}} / \mathbf{E}_{\mathrm{ir}(\mathrm{t})}}{\Delta \mathbf{E}_{\mathbf{r}} / \mathbf{E}_{\mathbf{r}(\mathbf{t})}}
$$

Keterangan :

$$
\begin{aligned}
\mathrm{RPr}= & \text { Rasio Pertumbuhan PDRB } \\
& \text { sektor dan subsektor } \\
& \text { pertanian, kehutanan dan } \\
& \text { perikanan Provinsi Jawa } \\
& \text { Timur }
\end{aligned}
$$

$\Delta \mathrm{E}_{\mathrm{ir}}=$ Perubahan PDRB Provinsi Jawa Timur disektor dan 


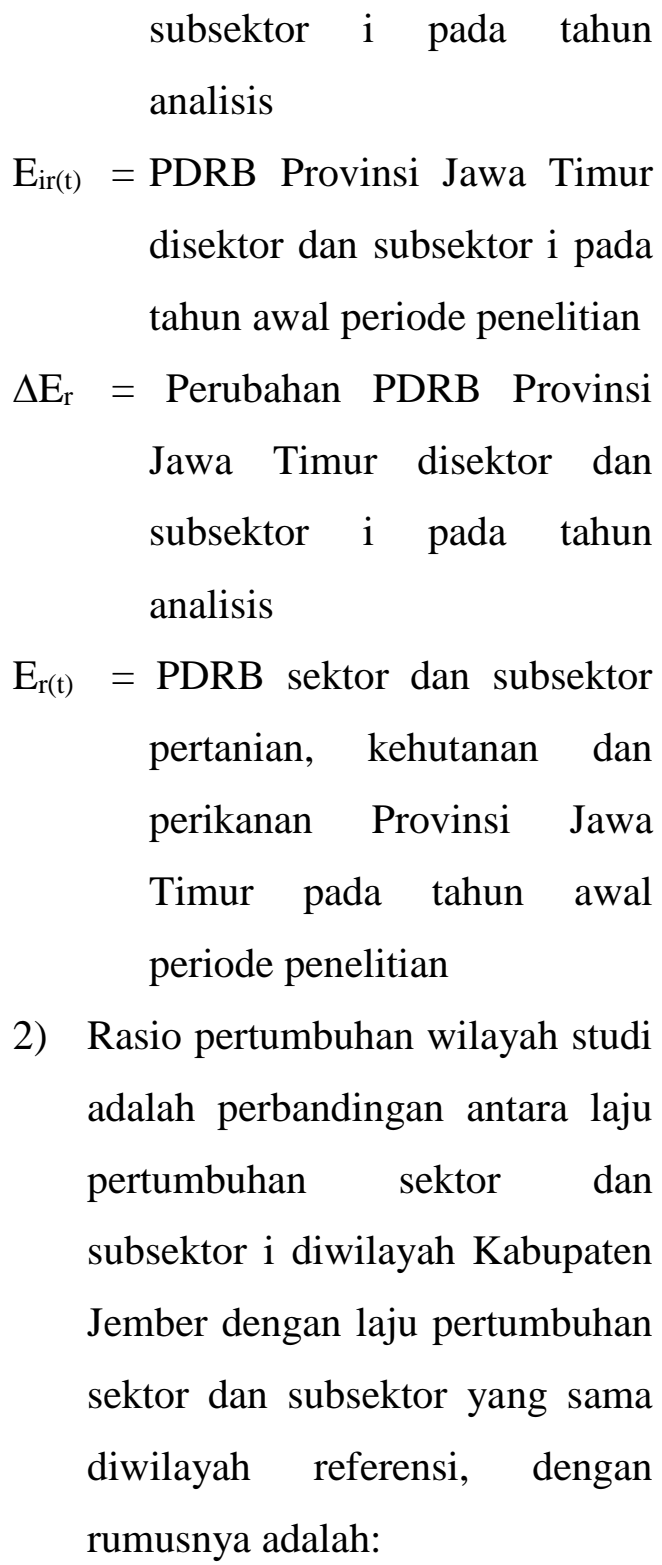$$
\operatorname{RPs}=\frac{\Delta \mathbf{E}_{\mathrm{ij}} / \mathbf{E}_{\mathrm{ij}(\mathbf{t})}}{\Delta \mathbf{E}_{\mathrm{ir}} / \mathbf{E}_{\mathrm{ir}(\mathrm{t})}}
$$

Keterangan :

RPr $=$ Rasio Pertumbuhan

Kabupaten Jember sektor dan

subsektor pertanian,

kehutanan dan perikanan

Provinsi Jawa Timur $\begin{aligned} \Delta \mathrm{E}_{\mathrm{ij}} & =\text { Perubahan PDRB Kabupaten } \\ & \text { Jember sektor dan subsektor } \mathrm{i} \\ & \text { pada tahun analisis } \\ \mathrm{E}_{\mathrm{ij}(\mathrm{t})} & =\text { PDRB Kabupaten Jember } \\ & \text { sektor dan subsektor i pada } \\ & \text { tahun awal periode penelitian } \\ \Delta \mathrm{E}_{\mathrm{ir}} & =\text { Perubahan PDRB Provinsi } \\ & \text { Jawa Timur sektor dan } \\ & \text { subsektor i pada tahun analisis } \\ \mathrm{E}_{\mathrm{ir}(\mathrm{t})} & =\text { PDRB Provinsi Jawa Timur } \\ & \text { sektor dan subsektor i pada } \\ & \text { tahun awal periode penelitian } \\ & \text { Menurut Yusuf (1999: 223-225) }\end{aligned}$

kombinasi hasil RPr dan RPs bisa menggambarkan kegiatan ekonomi unggulan dengan empat klasifikasi:

1) Nilai RPr (+) dan RPs (+) berarti kegiatan tersebut baik pada wilayah referensi maupun pada wilayah studi dan mempunyai pertumbuhan menonjol.

2) Nilai RPr (+) dan RPs (-) berarti kegiatan tersebut pada wilayah referensi pertumbuhannya menonjol akan tetapi pada wilayah studi pertumbuhannya belum menonjol.

3) Nilai RPr (-) dan RPs (+) berarti kegiatan tersebut pada wilayah referensi pertumbuhannya tidak menonjol akan tetapi pada 
wilayah studi pertumbuhannya menonjol.

4) Klasifikasi 4, adalah bila $\operatorname{RPr}(-)$ dan RPs (-) berarti kegiatan tersebut baik pada wilayah referensi maupun wilayah studi pertumbuhannya tidak menonjol.

4. Penentuan Bobot Penilaian Sektor Unggulan

Untuk melihat dan mengidentifikasi sektor unggulan di Provinsi Jawa Timur telah dilakukan berbagai macam penggunaan alat analisis. Dikarenakan menggunakan lebih dari satu alat analisis, maka dari masing-masing hasil analisis dengan menggunakan alat analisis ShiftShare, LQ dan MRP diberikan bobot penilaian dengan menentukan peringkat nilai yang ditetapkan untuk masing-masing sektor.

Pemberian peringkat untuk setiap sektor ekonomi di Provinsi Jawa Timur dilakukan dengan memberikan angka yang sesuai dengan jumlah sektor ekonomi sebanyak 17 (tujuh belas) sektor. Selanjutnya diberikan nilai 1 (satu) sampai dengan 17 (tujuh belas) sesuai dengan nilai dari masing-masing sektor.

PEMBAHASAN
Berdasarkan tujuan penelitian, data-data yang diperoleh dalam penelitian ini dianalisis dengan pendekatan kuantitatif yang disesuaikan dengan alat analisis yang digunakan. Dalam menentukan sektor dan sub sektor unggulan dilakukan dengan menganalisis dari sektor dan subsektor pertanian, kehutanan dan perikanan Kabupaten Jember pada Produk Domestik Regional Bruto (PDRB) Kabupaten Jember yang merupakan daerah penelitian dibandingkan dengan sektor dan subsektor pertanian, kehutanan dan perikanan pada Produk Domestik Regional Bruto (PDRB) Provinsi Jawa Timur yang merupakan daerah referensi.

Hasil dari analisis data dan pembahasan digunakan dengan alat analisis secara berturut-turut yakni analisis Shift-Share, analisis Location Quotient (LQ), dan Model Rasio Pertumbuhan (MRP). Hasil analisis yang telah diperoleh dengan menggunakan alat analisis tersebut selanjutnya dilakukan pembobotan untuk memperoleh gambaran tentang sektor dan subsektor ekonomi yang paling potensial.

\section{A. Analisis Shift-Share}


Dalam memberikan gambaran sektor dan subsektor pertanian, kehutanan dan perikanan yang berkembang dalam meningkatkan potensi ekonomi Kabupaten Jember dengan dibandingkan perkembangan ekonomi sektor dan subsektor pertanian, kehutanan dan perikanan Provinsi Jawa Timur digunakan alat analisis Shift-Share. Untuk mengetahui hasil analisis Shift Share dapat dilihat pada tabel 5 di bawah ini:

Tabel 1. Hasil Perhitungan Shift Share Sektor dan Subsektor Pertanian, Kehutanan dan Perikanan Kabupaten Jember 2010-2015

\begin{tabular}{|c|c|c|c|c|c|}
\hline No & Sektor & $\begin{array}{c}\text { Nij= } \\
\text { Eij*rn }\end{array}$ & $\begin{array}{l}\text { Mij= } \\
\text { Eij*(rin- } \\
\text { rn) }\end{array}$ & $\begin{array}{c}\text { Cij= } \\
\text { Eij*(rij- } \\
\text { rin) }\end{array}$ & $\begin{array}{c}D i j= \\
\text { Nij+Mij+Cij }\end{array}$ \\
\hline 1 & $\begin{array}{l}\text { Pertanian,Peternakan, } \\
\text { Perburuan \& Jasa } \\
\text { Pertanian }\end{array}$ & $2.003,64$ & $(594,12)$ & 670,38 & $2.079,90$ \\
\hline $\mathbf{a}$ & Tanaman Pangan & 620,98 & $(272,11)$ & 196,43 & 545,30 \\
\hline b & $\begin{array}{l}\text { Tanaman } \\
\text { Holtikultura }\end{array}$ & 211,62 & $(50,22)$ & 28,70 & 190,10 \\
\hline c & Tanaman Perkebunan & 757,61 & 66,51 & 199,28 & $1.023,40$ \\
\hline d & Peternakan & 390,12 & $(159,42)$ & 59,29 & 290,00 \\
\hline $\mathbf{e}$ & $\begin{array}{l}\text { Jasa Pertanian dan } \\
\text { Perburuan }\end{array}$ & 23,30 & 4,92 & 2,88 & 31,10 \\
\hline 2 & $\begin{array}{l}\text { Kehutanan dan } \\
\text { Penebangan Kayu }\end{array}$ & 61,92 & 84,96 & $(40,28)$ & 106,60 \\
\hline 3 & Perikanan & 138,72 & 177,89 & $(90,81)$ & 225,80 \\
\hline & Total & $2.204,28$ & $(331,27)$ & 539,29 & $2.412,30$ \\
\hline
\end{tabular}

Sumber : data diolah

Dari tabel di atas terlihat bahwa perekonomian Kabupaten Jember sektor dan subsektor pertanian, kehutanan dan perikanan selama periode 2010-2015 mengalami peningkatan sebesar Rp2.412,30 milyar. Peningkatan kinerja perekonomian di Provinsi Jawa Timur tersebut dapat dilihat dari sektor dan subsektor pertanian, kehutanan dan perikanan yang bernilai positif dimana sektor yang memberikan kontribusi terbesar adalah sektor Pertanian,Peternakan, Perburuan \& Jasa Pertanian sebesar Rp2.079,90 milyar dimana subsektor tanaman perkebunan menyumbang terbesar dibandingkan subsektor lainnya yaitu sebesar Rp1.023,40 milyar.

Kenaikan pertumbuhan ekonomi sektor dan subsektor pertanian, kehutanan dan perikanan di 
Kabupaten Jember disebabkan oleh beberapa faktor di antaranya pengaruh pertumbuhan ekonomi Provinsi Jawa Timur, pengaruh bauran industri dan pengaruh keunggulan kompetitif, untuk lebih jelasnya dapat dirinci sebagai berikut:

1. Pengaruh Pertumbuhan Ekonomi Provinsi Jawa Timur (Nij)

Pengaruh pertumbuhan ekonomi sektor dan subsektor pertanian, kehutanan dan perikanan Provinsi Jawa Timur (Nij) terhadap pertumbuhan ekonomi sektor dan subsektor pertanian, kehutanan dan perikanan Kabupaten Jember memberikan kontribusi positif sebesar Rp2.204,28 milyar. Apabila dilihat dari pertumbuhan ekonomi sektor dan subsektor pertanian, kehutanan dan perikanan Kabupaten Jember dibandingkan dengan tingkat pertumbuhan relatif sektor dan subsektor pertanian, kehutanan dan perikanan di tingkat provinsi menunjukkan bahwa secara ratarata sektor dan subsektor pertanian, kehutanan dan perikanan yang berada ditingkat kabupaten relatif lebih tinggi dari sektor dan subsektor pertanian, kehutanan dan perikanan ditingkat provinsi.

2. Pengaruh Bauran Industri (Mij) Pengaruh bauran industri (Mij) dalam perekonomian di Provinsi Jawa Timur memberikan kontribusi negatif sebesar Rp331,27 milyar. Dilihat dari output yang dihasilkan bauran industri sebagian besar sektor dan subsektor pertanian, kehutanan dan perikanan memiliki dampak positif dan dampak negatif. Nilai positif mempunyai arti bahwa tingkat pertumbuhan yang lebih cepat dari pertumbuhan sektor dan subsektor pertanian, kehutanan dan perikanan secara keseluruhan sedangkan nilai negatif mempunyai arti tingkat pertumbuhan yang lebih lambat dari pertumbuhan sektor ekonomi secara keseluruhan.

3. Pengaruh Keunggulan kompetitif (Cij)

Keunggulan kompetitif (Cij) disetiap sektor dan subsektor pertanian, kehutanan dan perikanan mengalami kenaikan dengan nilai total positif sebesar Rp539,29 milyar. 
B. Analisis Location Quotient (LQ)

Dalam menentukan sektor tersebut unggulan (potensial) atau tidak digunakan metode analisis Location Quotient (LQ). Dasar dari perhitungan LQ tersebut adalah teori basis ekonomi dimana akibat dari suatu industri menghasilkan barang dan jasa baik untuk pasar didaerah maupun untuk pasar di luar daerah yang mengakibatkan arus pendapatan akan mengalir ke daerah yang bersangkutan.
Kriteria sektor unggulan (potensial) mempunyai koefisien LQ>1, dimana sektor tersebut mempunyai prospek yang baik dalam peningkatan perekonomian Kabupaten Jember. Untuk kriteria sektor yang tidak unggulan (potensial) mempunyai koefisien LQ $<1$, dimana sektor tersebut tidak mempunyai prospek yang baik terhadap peningkatan perekonomian Kabupaten Jember.

\section{Tabel 2. Hasil Perhitungan Location Quotient (LQ) Sektor dan Subsektor Pertanian, Kehutanan dan Perikanan Kabupaten Jember, 2010- 2015}

\begin{tabular}{|c|c|c|c|c|c|c|c|c|c|}
\hline \multirow[t]{2}{*}{ No } & \multirow[t]{2}{*}{ Sektor } & \multicolumn{6}{|c|}{$\begin{array}{l}\text { LQ Sektor dan Subsektor Pertanian, } \\
\text { Kehutanan dan Perikanan Kabupaten } \\
\text { Jember }\end{array}$} & \multirow[t]{2}{*}{$\begin{array}{l}\text { Rata- } \\
\text { Rata }\end{array}$} & \multirow[t]{2}{*}{ Keterangan } \\
\hline & & 2010 & 2011 & 2012 & 2013 & 2014 & 2015 & & \\
\hline 1 & $\begin{array}{l}\text { Pertanian,Peternakan, } \\
\text { Perburuan \& Jasa } \\
\text { Pertanian }\end{array}$ & 1,12 & 1,12 & 1,13 & 1,16 & 1,16 & 1,17 & 1,14 & Sektor Basis \\
\hline $\mathbf{a}$ & Tanaman Pangan & 0,82 & 0,83 & 0,83 & 0,86 & 0,85 & 0,85 & 0,84 & $\begin{array}{l}\text { Sektor Non } \\
\text { Basis }\end{array}$ \\
\hline $\mathbf{b}$ & $\begin{array}{l}\text { Tanaman } \\
\text { Holtikultura }\end{array}$ & 0,96 & 0,95 & 0,96 & 0,98 & 0,98 & 0,97 & 0,97 & $\begin{array}{l}\text { Sektor Non } \\
\text { Basis }\end{array}$ \\
\hline c & Tanaman Perkebunan & 2,21 & 2,19 & 2,21 & 2,21 & 2,20 & 2,27 & 2,21 & Sektor Basis \\
\hline d & Peternakan & 0,88 & 0,86 & 0,86 & 0,89 & 0,91 & 0,89 & 0,88 & $\begin{array}{l}\text { Sektor Non } \\
\text { Basis }\end{array}$ \\
\hline $\mathbf{e}$ & $\begin{array}{l}\text { Jasa Pertanian dan } \\
\text { Perburuan }\end{array}$ & 0,94 & 0,94 & 0,90 & 0,92 & 0,93 & 0,94 & 0,93 & $\begin{array}{c}\text { Sektor Non } \\
\text { Basis }\end{array}$ \\
\hline 2 & $\begin{array}{l}\text { Kehutanan dan } \\
\text { Penebangan Kayu }\end{array}$ & 0,88 & 0,88 & 0,84 & 0,79 & 0,81 & 0,79 & 0,83 & $\begin{array}{l}\text { Sektor Non } \\
\text { Basis }\end{array}$ \\
\hline 3 & Perikanan & 0,41 & 0,40 & 0,40 & 0,37 & 0,36 & 0,36 & 0,38 & $\begin{array}{l}\text { Sektor Non } \\
\text { Basis }\end{array}$ \\
\hline
\end{tabular}

\section{Sumber : Data Diolah}

Dari tabel di atas dapat dilihat bahwa terdapat 1 sektor dan 1 subsektor yang mempunyai rata-rata
LQ>1 atau sektor dan subsektor yang unggulan (potensial) dan sekaligus merupakan basis ekonomi yang bisa 
dikembangkan lebih lanjut yaitu sektor pertanian, peternakan, perburuan \& jasa pertanian dan subsektor tanaman perkebunan.

Sektor dan subsektor tersebut mampu melayani kebutuhan pasar baik di dalam maupun di luar Kabupaten Jember sedangkan sektor dan subsektor lainnya belum mampu melayani pasar di Kabupaten Jember atau belum mampu memasarkan hasil sektor tersebut ke daerah lain.

\section{Analisis Model Rasio Pertumbuhan (MRP)}

Analisis Model Rasio Pertumbuhan (MRP) dilakukan setelah melakukan analisis Location Quotient (LQ). Analisis Model Rasio Pertumbuhan (MRP) digunakan untuk mengetahui perbandingan laju pertumbuhan sektor dan subsektor dimasing-masing wilayah baik Kabupaten Jember maupun Provinsi Jawa Timur. Pada Model Rasio Pertumbuhan dibagi atas 2 (dua) yaitu rasio pertumbuhan wilayah referensi
(RPr) dan rasio pertumbuhan wilayah studi (RPs). Untuk wilayah referensi adalah Provinsi Jawa Timur dan wilayah studi adalah Kabupaten Jember.

\section{Model Rasio Pertumbuhan} (MRP) merupakan pengembangan atau modifikasi dari model ShiftShare dimana dengan metode ShiftShare hasil yang dicapai adalah hasil angka riil yang terdiri dari kontribusi dan pertumbuhan sedangkan pada model MRP menghasilkan pertumbuhan berupa angka koefisien. Kategori angka koefisien ini adalah pertumbuhan suatu aktifitas positif (+) atau negatif (-). Untuk RPr atau RPs > 1, maka RPr dan RPs secara nominal positif (+) dan sebaliknya bila RPr atau RPs $<1$, maka RPr dan RPs tersebut secara nominal negatif (-). Untuk mengetahui hasil analisis model rasio pertumbuhan dapat dilihat pada tabel 7 di bawah ini:

\section{Tabel 3. Hasil Perhitungan Model Rasio Pertumbuhan Sektor dan Subsektor Pertanian, Kehutanan dan Perikanan Provinsi Jawa Timur dan Kabupaten Jember, 2010-2015}

\begin{tabular}{llcccc}
\hline \multirow{2}{*}{ No } & \multicolumn{1}{c}{ Sektor } & \multicolumn{3}{c}{ Model Rasio Pertumbuhan (MRP) } \\
\cline { 3 - 6 } & & \multicolumn{3}{c}{ RPr } & \multicolumn{2}{c}{ RPs } \\
\cline { 2 - 6 } & & $\mathrm{R}$ & $\mathrm{N}$ & $\mathrm{R}$ & $\mathrm{N}$ \\
\hline $\mathbf{1}$ & $\begin{array}{l}\text { Pertanian, Peternakan, Perburuan \& } \\
\text { Jasa Pertanian }\end{array}$ & 0,70 & - & 0,95 & - \\
\hline a & Tanaman Pangan & 0,56 & - & 0,80 & - \\
\hline
\end{tabular}




\begin{tabular}{llrrrr}
\hline b & Tanaman Holtikultura & 0,76 & - & 0,82 & - \\
\hline c & Tanaman Perkebunan & 1,09 & + & 1,23 & + \\
\hline d & Peternakan & 0,59 & - & 0,68 & - \\
\hline e & Jasa Pertanian dan Perburuan & 1,21 & + & 1,22 & + \\
\hline $\mathbf{2}$ & Kehutanan dan Penebangan Kayu & 2,37 & + & 1,57 & + \\
\hline $\mathbf{3}$ & Perikanan & 2,28 & + & 1,49 & + \\
\hline
\end{tabular}

Sumber : Data Diolah

Untuk mengkombinasikan hasil

RPr dan RPs bisa diklasifikasikan gambaran kegiatan ekonomi sektor dan subsektor pertanian, kehutanan dan perikanan pada Kabupaten Jember dengan cara empat klasifikasi:

1. Klasifikasi 1, adalah nilai $\mathrm{RPr}$ (+) dan RPs (+) berarti kegiatan tersebut baik pada wilayah referensi maupun pada wilayah studi dan mempunyai pertumbuhan menonjol. Dengan melihat pada tabel 7 maka sektor dan subsektor tersebut adalah subsektor tanaman perkebunan, subsektor jasa pertanian dan perburuan, sektor kehutanan dan penebangan kayu, dan sektor perikanan.

2. Klasifikasi 2, adalah bila $\mathrm{RPr}$ (+) dan RPs (-) berarti kegiatan tersebut pada wilayah referensi pertumbuhannya menonjol akan tetapi pada wilayah studi pertumbuhannya belum menonjol. Dengan melihat pada tabel 7 maka tidak ada sektor yang memenuhi klasifikasi tersebut.

3. Klasifikasi 3, adalah bila $\operatorname{RPr}(-$ ) dan RPs (+) berarti kegiatan tersebut pada wilayah referensi pertumbuhannya tidak menonjol akan tetapi pada wilayah studi pertumbuhannya menonjol. Dengan melihat pada tabel 7 maka tidak ada sektor yang memenuhi klasifikasi tersebut.

4. Klasifikasi 4, adalah bila $\mathrm{RPr}(-$ ) dan RPs (-) berarti kegiatan tersebut baik pada wilayah referensi maupun wilayah studi pertumbuhannya tidak menonjol. Dengan melihat pada tabel 7 maka sektor tersebut adalah sektor pertanian, peternakan, perburuan \& jasa pertanian, sektor tanaman pangan, sektor tanaman holtikultura, dan sektor peternakan. 
Analisis Potensi Ekonomi Di Sektor dan... (Ahmad Rizani)

D. Metode Pembobotan Peringkat

Sektor dan Subsektor

Unggulan

Hasil analisis yang telah diperoleh dengan menggunakan alat analisis Shift-Share, Location

Quotient (LQ), dan Model Rasio
Pertumbuhan (MRP) selanjutnya diberi bobot untuk memperoleh gambaran tentang sektor-sektor ekonomi yang potensial sebagaimana nampak pada tabel 9 di bawah ini: 
Tabel 4. Hasil Pembobotan Berdasarkan Analisis Shift-Share, Location Quotient (LQ), dan Model Rasio Pertumbuhan (MRP) Sektor dan Subsektor Pertanian, Kehutanan dan Perikanan Kabupaten Jember, $2010-2015$

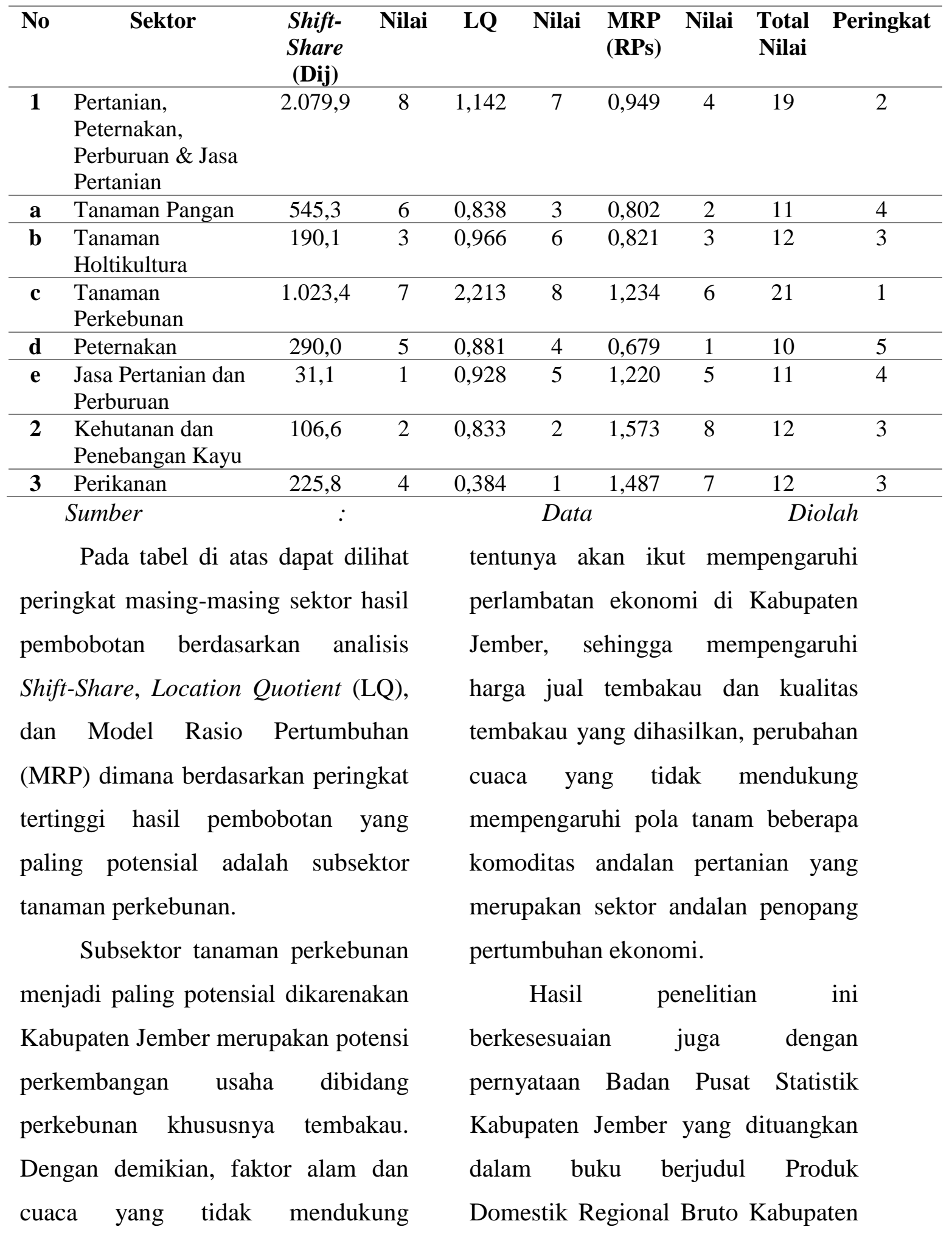


Jember Menurut Lapangan Usaha 2010 - 2015 yang menyatakan bahwa lapangan usaha kategori pertanian, kehutanan, dan perikanan memberi kontribusi terbesar terhadap total PDRB dimana lapangan usaha subkategori tanaman perkebunan merupakan penyumbang terbesar terhadap lapangan usaha kategori pertanian, kehutanan, dan perikanan.

\section{KESIMPULAN}

Berdasarkan hasil analisis data yang dilakukan serta tujuan yang ingin dicapai dalam penelitian ini, maka dapat dirumuskan beberapa kesimpulan sebagai berikut:

Hasil analisis Shift-Share
menunjukkan bahwa struktur
perekonomian dari tahun pengamatan
2010-2015 Kabupaten Jember dibandingkan dengan Provinsi Jawa Timur mengalami peningkatan sebesar Rp2.412,3 milyar, hal tersebut disebabkan beberapa faktor yakni pengaruh pertumbuhan ekonomi Provinsi Jawa Timur sebesar Rp2.204,3 milyar, pengaruh bauran industri sebesar minus Rp331,3 milyar dan pengaruh keunggulan kompetitif sebesar Rp539,3 milyar.
Berdasarkan analisis LQ sektor unggulan di Kabupaten Jember selama periode 2010-2015 terdapat 1 sektor dan 1 subsektor yang mempunyai rata-rata $L Q>1$ atau sektor dan subsektor yang unggulan (potensial) dan sekaligus merupakan basis ekonomi yang bisa dikembangkan lebih lanjut yaitu sektor pertanian, peternakan, perburuan \& jasa pertanian dan subsektor tanaman perkebunan.

Hasil perhitungan analisis Model Rasio Pertumbuhan (MRP) menunjukkan bahwa berdasarkan kombinasi RPr dan RPs sektor dan subsektor dominan pertumbuhannya meliputi subsektor tanaman perkebunan, subsektor jasa pertanian dan perburuan, sektor kehutanan dan penebangan kayu, dan sektor perikanan

Hasil pembobotan berdasarkan analisis Shift-Share, Location Quotient (LQ), dan Model Rasio Pertumbuhan (MRP) diperoleh subsektor berdasarkan peringkat tertinggi hasil pembobotan yang paling potensial yaitu subsektor tanaman perkebunan. 
Dari hasil penelitian yang diperoleh maka dapat dikemukakan beberapa saran-saran yang bisa dipertimbangkan oleh pemerintah Kabupaten Jember dalam menyusun perencanaan pembangunan ekonomi untuk meningkatkan potensi ekonomi daerah sebagai berikut:

Agar pembangunan daerah Kabupaten Jember lebih berhasil maka Pemerintah Kabupaten Jember haruslah menentukan prioritas pembangunan yang didasarkan atas potensi ekonomi yang dimilikinya melalui pengembangan sektor dan subsektor unggulan atau potensial.

Supaya tidak terjadi kesenjangan dan ketimpangan antar sektor, maka Pemerintah Kabupaten Jember haruslah memanfaatkan sektor dan subsektor yang unggulan dan potensial agar kesejahteraan masyarakat lebih meningkat. Upaya yang dapat dilakukan di antaranya adalah menciptakan iklim investasi yang kondusif melalui kebijakankebijakan daerah yang merangsang timbulnya investasi baru seperti kemudahan perijinan dan melakukan pemetaan tata ruang dan wilayah yang mendukung investasi.

\section{DAFTAR PUSTAKA}

Arsyad, Lincolin, 2004, Ekonomi Pembangunan, Edisi Keempat, STIE YKPN, Yogyakarta

Badan Perencanaan Pembangunan Daerah Pemerintah Provinsi Jawa Timur, 2015, Booklet Informasi Perencanaan

Pembangunan Jawa Timur,

Bappeda Jawa Timur

Badan Perencanaan Pembangunan Nasional dan UNDP, 2007, Studi Evaluasi Dampak Pemekaran Daerah Tahun 2001-2007, Edisi Juli 2008, BRIDGE, Jakarta

Badan Pusat Statistik Indonesia, Statistik Indonesia 2016, BPS Statistik Indonesia

Badan Pusat Statistik Provinsi Jawa Timur, Produk Domestik Regional Bruto Provinsi Jawa Timur Menurut Lapangan Usaha 2010-2015, BPS Provinsi Jawa Timur

Bendavid-Val, Avron, 1991, Regional and Local Economic Analysis for Practitioner, Four Edition, 
Sage Publication inc,

Edisi Pertama, Bappeda

California, USA.

Provinsi Nusa Tenggara Barat,

Blakely, Edward $\mathrm{J}$ and Bradshaw, Mataram.

2002, Planning local Economic

Development : Theory and

Practice, Third Edition, Sage

Publications, California, USA.

Boediono, 1999, Teori Pertumbuhan

Ekonomi, Edisi Pertama,

Penerbit BPFE, Yogyakarta

Hanham, R.Q., and Shawn, B., 2000,

Shift-Share Analysis and

Change in Japanese

Manufacturing Employment,

Growth and Change, Vol. 31,

108-123.

Hassan, Mohd Khairul Hisyam,

Zakariah Abdul Rashid, Khalil

Abdul Hamid (2011), East

Coast Economic Region From

The Perspective of Shift-Share

Analysis, International Journal

of Business and Society, Vol.

12, No. 1, 2011, 79-88.

Kuncoro, M., 2004, Otonomi dan

Pembangunan Daerah :

Reformasi, Perencanaan,

Strategi, dan Peluang, Penerbit

Erlangga, Jakarta.

Munir, Badrul, 2002, Perencanaan

Pembangunan Daerah Dalam

Persfektif Otonomi Daerah,

Nelson, C., Arthur, William, P., Drumond, and David., Sawicki, 1994, Economic Base : Analysis of Employment Trends by Economic Sector, Economic Development Review, Summer, 32-36.

Rex, T.R., 1997, Key Arizona Economic Activities Identified, Arizona State University, Monthly Newsletter on The Arizona Economic, Vol. IV, No. 9, 1-6.

Richardson, Harry, 1977, DasarDasar Ilmu Ekonomi Regional, terjemahan oleh Paul Sihotang, Fakultas Ekonomi Universitas Indonesia, Jakarta.

Sjafrizal, 2008, Ekonomi Regional :

Teori dan Aplikasi, Baduose Media, Padang.

Soepono, Prasetyo, 1993, Analisis Shift-Share Perkembangan dan Penerapan, Jurnal Ekonomi dan Bisnis, No. 1 Tahun III: 43-54.

Sukirno, Sadono, 2007, Makroekonomi Modern Perkembangan Pemikiran Dari Klasik Hingga Keynesian Baru, 
PT. Raja Grafindo Persada, Jakarta.

Sukirno, Sadono, 2011, Ekonomi Pembangunan : Proses, Masalah, dan Dasar Kebijaksanaan, Lembaga Penerbit Fakultas Ekonomi UI dan Bina Grafika, Jakarta.

Tambunan, Tulus T.H, 2003,

Perekonomian Indonesia,

Ghalia Indonesia, Jakarta

Tarigan, Robinson, 2007, Ekonomi Regional Teori dan Aplikasi, PT Bumi Aksara, Jakarta.

Todaro, M.P, 2000, Pembangunan Ekonomi di Dunia Ketiga, Edisi Ketujuh, Alih Bahasa Harris

Munandar, Penerbit Airlangga, Jakarta.

Widodo, Tri, 2006, Perencanaan Pembangunan : Aplikasi Komputer (Era Otonomi Daerah), Penerbit UPP STIM YKPN, Yogyakarta.
Wijaya, A. 1996. Jurnal Ekonomi Pembangunan Pilihan Pembangunan Industri : Kasus DKI Jakarta, No IV (2), Jakarta.

Yeo, Benjamin J.K., 2010, Driving the Knowledge Economy : Explaining the Impact of Regional Innovation Capacity on Economic Performance, Contemporary Management Research Pages 71-86, Vol. 6, No. 1, March 2010.

Yusuf, Maulana, 1999, Model Rasio Pertumbuhan (MRP) Sebagai Salah Satu Alat Analisis Alternatif Dalam Perencanaan Wilayah Dan Kota, Aplikasi Model : Bangka Belitung, Ekonomi dan Keuangan Indonesia, Vol. XLVII, No. 2 : 221-233. 